\title{
Clinico-radiological Observations in Meconium Aspiration Syndrome
}

\author{
Susana Lama, ${ }^{1}$ Shyam Kumar Mahato, ' Nagendra Chaudhary,, 1,4 Nikhil Agrawal,' Santosh Pathak, ${ }^{2}$ Om \\ Prakash Kurmi, ${ }^{3,4}$ Baldev Bhatia, ${ }^{5}$ Kailash Nath Agarwal ${ }^{1}$ \\ 'Department of Pediatrics, Universal College of Medical Sciences, Bhairahawa, Nepal, ${ }^{2}$ Department of Pediatrics, Chitwan \\ Medical College, Bharatpur, Nepal, ${ }^{3}$ Nuffield Department of Population Health, Clinical Trial Service Unit \& Epidemiological \\ Studies Unit, University of Oxford, Oxford, UK, ${ }^{4}$ Centre for Population Health Research, Bhairahawa, Nepal, ${ }^{5}$ Department of \\ Pediatrics, Heritage Institute of Medical Sciences, Varanasi, India.
}

\section{ABSTRACT}

Introduction: To understand and report the prevalence of meconium aspiration syndrome and the clinico-radiological features in a tertiary care hospital of western Nepal.

Methods: An observational study carried out for a year in 2014-15 in all babies with MAS. Clinical and radiological profiles of MAS in relation to gender, gestational age, mode of delivery, birth weight, Apgar score, thickness of meconium, age at admission and the immediate outcome were studied.

Results: Out of 584 admitted newborns (male=389; female=186) during the study period, 78 (13.4\%) had meconium aspiration syndrome with male: female ratio of 1.2:1. Majority of babies admitted to NICU had thick meconium $[\mathrm{n}=52(66.7 \%)]$. There was no statistical significant difference in various parameters such as Apgar score at 1 and 5 minutes, respiratory distress, birth asphyxia, duration of oxygen use, MAS severity and chest x-ray in those with thick MAS compared to thin. Among all newborns with MAS, 59\% ( $n=46)$ had abnormal radiological findings with over two-folds in those with thick MAS (71.7\%)] compared to thin (28\%). Hyperinflation (47.8\%), diffuse patchy infiltration (37\%), consolidation $(21.7 \%)$ collapse $(8.7 \%)$, right lung fissure $(6.5 \%)$ and pneumothorax $(8.7 \%)$ were the abnormal radiological findings seen in MAS babies. The odds of having APGAR score at 1 minute at least 7 or more was twice unlikely in those having thick meconium compared to thin $(\mathrm{P}=0.02)$

Conclusions: Thick meconium is relatively common with more significant abnormal radiological findings and low Apgar score.

Keywords: meconium aspiration syndrome; thick meconium; thin meconium; chest $x$-ray.

\section{INTRODUCTION}

Meconium aspiration syndrome (MAS), one of the most common causes of neonatal respiratory distress, is commonly noticed in babies with increased gestational age. ${ }^{1,2}$ MSAF has been associated with fetal distress and hence has been recognized as a predictor of poor fetal outcome. Meconium staining of the amniotic fluid (MSAF) is usually carried out in approximately 10-15\% of childbirths, of which approximately $5-12 \%$ of new born are diagnosed with MAS. ${ }^{3-5}$
Many perinatal risk factors have been associated with meconium aspiration including placental insufficiency, maternal hypertension, maternal diabetes mellitus, preeclampsia, oligohydramnios, and maternal tobacco use. But, perhaps the most significant risk factor for meconium aspiration is intrauterine growth retardation (IUGR) and post-term delivery. There is a wide variation

Correspondence: Dr. Nagendra Chaudhary, Department of Pediatrics, Universal College of Medical Sciences, Bhairahawa, Nepal. Email: enagendra@hotmail.com, Phone : +977-9857012029. 
in the radiological finding in MAS, of which the most common are diffuse patchy infiltrations, hyperinflation, consolidation and collapse.

The main aim of this study was to understand the prevalence of MAS in tertiary care hospital of western Nepal and also report the clinico-radiological profiles of newborn with MAS.

\section{METHODS}

An observational cross sectional study was carried out in Neonatal Intensive Care Unit of Department of Pediatrics at Universal College of Medical Sciences, Bhairahawa, Nepal from August 2014 to July 2015. Newborns admitted to the neonatal intensive care unit were screened for MAS. MAS diagnosis among newborn included: a) presence of meconium stained amniotic fluid (MSAF) and staining of nails, skin and cord with meconium; b) presence of meconium below the vocal cords; c) clinical respiratory distress shortly after birth; and/or abnormal chest x-ray consistent with aspiration pneumonitis. All babies fulfilling the first and any of the remaining criteria for diagnosing MAS admitted to NICU, during the above mentioned period were included in the study. We studied the clinical and radiological (chest $x$ ray) profiles of MAS in relation to gender, gestational age, mode of delivery, birth weight, apgar score, thickness of meconium, age at admission and the immediate outcome. Newborns were subgrouped into two categories, thin and thick MSL. Thin MSL was defined as liquor having greenish yellow in color whereas liquor having dark green or tarry black or muddy in color and of thick consistency was graded as thick MSL.

Apgar score at 1 minute and 5 minute was assessed and gestational age assessment was done by LMP and confirmed with Ballard's score. Respiratory distress was monitored using Downe's scoring system. All infants with the diagnosis of meconium aspiration syndrome (thick and thin) were managed as per neonatal resuscitation programme (NRP) guidelines. All deliveries in the hospital were attended by a pediatric resident trained to follow the research protocol. All MAS babies were admitted and treated in NICU with oxygen and intravenous fluids. Antibiotics, inotropic support, and ventilator support was given as and when required following routine investigations for hemoglobin, total and differential leucocyte counts, platelets and C-reactive protein. Blood culture and renal function test were carried out. For transient metabolic disturbances, blood glucose, serum calcium, electrolytes and arterial blood gases ( $A B G$ ) were done. Radiological assessment was done by portable $x$-ray machine immediately after $\mathrm{NICU}$ admission and radiologists were asked to provide very specific details regarding $\mathrm{x}$-ray findings.

Newborns with congenital anomalies having medical or surgical significance were excluded from the study. Descriptive analysis was done using mean and percentage. Heterogeneity test was calculated using Chi square was used for categorical data and t-test continuous variable. Logistic regression was used to estimate the odds ratio of types of meconium for different radiological and non-radiological tests after adjusting for gender, oxygen used, gestation, admission age, and birth weight. $\mathrm{P}$ Value $<0.05$ was considered statistically significant. Data analysis was done by using Stata 13 software.

\section{RESULTS}

Out of 584 admitted newborns (male $=389$; female $=186$ ) during the study period, $78(13.4 \%)$ babies had MAS, of which $71.8 \%(n=56)$ were males and rest $28.2 \%(n=22)$ females. Babies were divided into two groups; thin and thick meconium for further analysis. Thick and thin MAS constituted $66.7 \%$ $(n=52)$ and $33.3(n=26)$ respectively (Table 1$)$. The proportion of both males and females having thick meconium was greater than those with thin meconium $(P=0.032)$. The mean birth weights $(S D)$ of babies with thin and thick meconium were $2805.5 \mathrm{gm}(452.8 \mathrm{gm})$ and $2898.8 \mathrm{gm}(611.2 \mathrm{gm})$ respectively.

There was no significant statistical difference in terms of mode of delivery, duration of admission after birth, gestational age, birth weight and stay in NICU among those with thick and thin meconium (Table 1).

\begin{tabular}{|c|c|c|c|}
\hline \multirow{2}{*}{\multicolumn{4}{|c|}{\begin{tabular}{|c|}
$\begin{array}{l}\text { Table 1. General characteristics of ne } \\
\text { meconium aspiration syndrome (MAS). }\end{array}$ \\
Types of meconium
\end{tabular}}} \\
\hline & & & \\
\hline $\begin{array}{l}\text { Charac- } \\
\text { teristics }\end{array}$ & $\begin{array}{l}\text { Thin } \\
\text { n (\%) }\end{array}$ & $\begin{array}{l}\text { Thick } \\
\text { n (\%) }\end{array}$ & $\begin{array}{l}P \\
\text { value }\end{array}$ \\
\hline Total MAS & 26 (33.3) & $52(66.7)$ & \\
\hline \multicolumn{4}{|l|}{ Gender } \\
\hline Male & 19 (33.9) & $37(66.1)$ & 0.032 \\
\hline Female & 7 (31.8) & $15(68.2)$ & \\
\hline \multicolumn{4}{|l|}{$\begin{array}{l}\text { Mode of } \\
\text { delivery }\end{array}$} \\
\hline Normal & $11(31.4)$ & $24(68.6)$ & 0.104 \\
\hline $\begin{array}{l}\text { Caesarean } \\
\text { section }\end{array}$ & 15 (34.9) & $28(65.1)$ & \\
\hline $\begin{array}{l}\text { Duration of } \\
\text { admission } \\
\text { after birth }\end{array}$ & & & \\
\hline $\begin{array}{l}\text { Within an } \\
\text { hour }\end{array}$ & 22 (32.3) & $46(67.6)$ & \\
\hline
\end{tabular}




\begin{tabular}{|c|c|c|c|}
\hline 1-2 hours & $2(33.3)$ & $4(66.7)$ & 0.529 \\
\hline 3-4 hours & $2(50.0)$ & $2(50.5)$ & \\
\hline \multicolumn{4}{|c|}{$\begin{array}{l}\text { Gestational } \\
\text { age (in } \\
\text { weeks) }\end{array}$} \\
\hline $37-41$ & 23 (35.9) & $41(64.1)$ & NS \\
\hline$>41$ & $3(21.4)$ & $11(17.9)$ & \\
\hline mean $\pm S D$ & $39.5 \pm 1.7$ & $\begin{array}{l}39.9 \\
\pm 1.8\end{array}$ & \\
\hline \multicolumn{4}{|l|}{$\begin{array}{l}\text { Birth weight } \\
\text { (in gm) }\end{array}$} \\
\hline$<2000$ & $1(25.0)$ & $3(75.0)$ & NS \\
\hline 2000-2499 & $4(26.7)$ & $11(73.3)$ & \\
\hline$\geq 2500$ & $21(35.6)$ & $38(64.4)$ & \\
\hline mean $\pm S D$ & $2805.5 \pm 452.8$ & 2898.8 & \pm 611.2 \\
\hline \multicolumn{4}{|l|}{$\begin{array}{l}\text { Stay in NICU } \\
\text { (in days) }\end{array}$} \\
\hline One & $7(25.9)$ & $20(74.1)$ & NS \\
\hline $2-4$ & $6(37.5)$ & $10(62.5)$ & \\
\hline $5-12$ & $13(37.1)$ & 22 (62.9) & \\
\hline mean $\pm S D$ & $4.0 \pm 2.6$ & $3.5 \pm 2.7$ & \\
\hline \multicolumn{4}{|l|}{$\begin{array}{l}\text { Stay in } \\
\text { hospital }\end{array}$} \\
\hline $\begin{array}{l}\text { Left against } \\
\text { medical } \\
\text { advice }\end{array}$ & $3(20.0)$ & $12(80.0)$ & \\
\hline Discharged & $22(36.7)$ & 38 (63.3) & \\
\hline Dead & $1(33.3)$ & $2(66.7)$ & \\
\hline
\end{tabular}

Similarly, comparison of various parameters such as Apgar score at 1 and 5 minutes, respiratory distress, birth asphyxia, duration of oxygen use, MAS severity and chest $\mathrm{x}$-ray showed no statistical significance among the two groups (Table 2).

\begin{tabular}{|lll|}
\hline \multicolumn{3}{|c|}{$\begin{array}{l}\text { Table 2. Comparison of outcomes in babies with } \\
\text { thin and thick meconium. }\end{array}$} \\
\hline $\begin{array}{l}\text { Types of } \\
\text { meconium } \\
\text { Thin } \mathbf{n}(\%)\end{array}$ & Thick $\mathbf{n}(\%)$ \\
APGAR score at 1 & \\
$\begin{array}{l}\text { minute } \\
<=3\end{array}$ & $4(19.0)$ & $17(80.9)$ \\
$4-6$ & $11(34.5)$ & $21(65.6)$ \\
$\geq 7$ & $11(44.0)$ & $14(56.0)$ \\
APGAR score at 5 & \\
minute & $1(25.0)$ & $3(75.0)$ \\
$<=3$ & $3(16.7)$ & $15(83.3)$ \\
$4-6$ & $22(39.3)$ & $34(60.7)$ \\
$\geq 7$ & &
\end{tabular}

\begin{tabular}{|c|c|c|}
\hline \multicolumn{3}{|l|}{$\begin{array}{l}\text { Respiratory } \\
\text { distress (Downes' } \\
\text { score) }\end{array}$} \\
\hline \multicolumn{3}{|l|}{$\begin{array}{l}\text { At admission } \\
(n=78)\end{array}$} \\
\hline$<4$ & $7(28.0)$ & $18(34.6)$ \\
\hline $4-6$ & $10(35.7)$ & $18(64.3)$ \\
\hline$>6$ & $9(36.0)$ & $16(64.0)$ \\
\hline \multicolumn{3}{|l|}{$\begin{array}{r}12 \text { hours from } \\
\text { admission }(n=48)\end{array}$} \\
\hline$<4$ & $3(100.0)$ & . \\
\hline $4-6$ & $9(29.0)$ & $22(71.0)$ \\
\hline$>6$ & $6(42.9)$ & $8(57.1)$ \\
\hline \multicolumn{3}{|l|}{$\begin{array}{r}24 \text { hours from } \\
\text { admission }(n=33)\end{array}$} \\
\hline$<4$ & 0 & $1(100.0)$ \\
\hline $4-6$ & $10(38.5)$ & $16(61.5)$ \\
\hline$>6$ & $2(33.3)$ & $4(66.7)$ \\
\hline \multicolumn{3}{|l|}{ Birth Asphyxia } \\
\hline No & $10(41.7)$ & $14(58.3)$ \\
\hline Moderate & $12(36.4)$ & $21(63.6)$ \\
\hline Severe & $4(19.0)$ & $17(81)$ \\
\hline \multicolumn{3}{|l|}{ Oxygen used } \\
\hline No & $7(30.4)$ & $16(69.6)$ \\
\hline Yes & $19(34.5)$ & $36(65.5)$ \\
\hline$<24$ hours & $5(38.5)$ & $8(61.5)$ \\
\hline $24-47$ hours & $7(29.2)$ & $17(70.8)$ \\
\hline 48-71 hours & $3(37.5)$ & $5(62.5)$ \\
\hline$\geq 72$ hours & $4(40.0)$ & $6(60.0)$ \\
\hline \multicolumn{3}{|l|}{ MAS severity } \\
\hline Mild & 19 (33.3) & $38(66.7)$ \\
\hline Moderate & $4(57.1)$ & $3(42.9)$ \\
\hline Severe & $3(21.4)$ & 11 (78.6) \\
\hline \multicolumn{3}{|l|}{ Chest X-ray } \\
\hline Normal & $13(40.6)$ & $19(59.4)$ \\
\hline Abnormal & $13(28.3)$ & $33(71.7)$ \\
\hline
\end{tabular}

Statistically not significant difference among the two groups

Among all newborns diagnosed with MAS, 59\% ( $n=46)$ babies had abnormal radiological findings, over two-folds greater in those with thick meconium $(71.7 \%)$ compared to thin $(28 \%)$. Hyperinflation $(47.8 \%)$ diffuse patchy infiltration $(37 \%)$, consolidation $(21.7 \%)$, collapse $(8.7 \%)$ right lung fissure $(6.5 \%)$ and pneumothorax $(8.7 \%)$ were the abnormal radiological findings seen in MAS babies irrespective of the meconium thickness. There was no statistical significance in the occurrence of any abnormal radiological picture between the two groups (Table 3). 


\begin{tabular}{|c|c|c|}
\hline \multirow{2}{*}{ Characteristics } & \multicolumn{2}{|c|}{ Types of meconium } \\
\hline & Thin $\mathrm{n}(\%)$ & Thick n (\%) \\
\hline $\begin{array}{l}\text { Total abnormal } \\
\text { x-ray }\end{array}$ & $13(28.3)$ & $33(71.7)$ \\
\hline Hyperinflation & $6(27.3)$ & $16(72.7)$ \\
\hline $\begin{array}{l}\text { Diffuse patch } \\
\text { infiltration }\end{array}$ & $5(29.4)$ & $12(70.6)$ \\
\hline Consolidation & $4(40.0)$ & $6(60.0)$ \\
\hline Collapse & $0(0.0)$ & $4(100.0)$ \\
\hline $\begin{array}{l}\text { Right lung fissure } \\
\text { (fluid) }\end{array}$ & $1(33.3)$ & $2(66.7)$ \\
\hline Pneumothorax & $1(25.0)$ & $3(75.0)$ \\
\hline
\end{tabular}

Statistically not significant difference among the two groups

The adjusted odds ' ratio with $95 \%$ confidence interval for thick meconium to abnormal chest $x$-ray and Apgar at 1 minute $\geq 7$ was $1.61(0.032,3.20)$ and -2.09 $(-3.91,-0.28)$ respectively.

\section{DISCUSION}

Meconium aspiration syndrome (MAS) is an important cause of neonatal mortality and morbidity in neonatal intensive care units (NICUs) with the proportion ranging in between $10.5-16.1 \% .^{6,7}$ The proportion of newborns with MAS admitted to NICU was $13.4 \%$, in the present study. Although the ratio of occurrence of MAS among all admitted babies did not show sex differences, there was male preponderance (1.2:1) among all MAS babies. A study conducted by Satish et al (2014) also showed similar findings. ${ }^{8}$

The present and earlier studies ${ }^{6,9}$ suggest higher rates of LSCS in comparison to normal delivery in MAS babies. In contrast Berkus et $\mathrm{al}^{10}$ showed lower LSCS rates (10.8\%) compared to spontaneous deliveries (76.4\%) in both thick and thin meconiums (babies). Likewise, $59.5 \%$ babies were delivered normally and $30.4 \%$ babies underwent caesarean in babies with thick meconium. ${ }^{10}$ It may be explained due to better health facilities to assess the fetal wellbeing.

Although neonatal distress often requires immediate NICU admission but chemical pneumonitis in MAS babies further increases the risk of respiratory distress leading to immediate NICU admission. In the present study majority of MAS cases $(87.2 \% ; n=68)$ were admitted in less than one hour as was also noticed in another study from Pakistan. ${ }^{11}$ The mean duration of hospital admissions in babies with thin and thick meconium were 4 days and 3.5 days with standard deviations of
2.6 days and 2.7 days. Majority of babies required admission of 5-12 days in our study. The overall duration of admission in thick meconium was comparatively more than in thin meconium but the result was statistically insignificant. Similar observations were made by Anwar et $\mathrm{al}^{11}$ the average duration of admission in MAS babies being 5-7 days with higher mortality in babies who were admitted for less than one day. In our study, three babies died (thin MAS $=1$; thick MAS = 2) although all of them were admitted within an hour of being born. Hyperinflations with patchy opacity were the radiological findings in all expired cases. Baby with thin meconium received 30 hours of ventillatory support and died in 68 hours of life where as other two babies with thick meconium received ventillatory support for 1 and 24 hours and died in 42 and 48 hours respectively. Although the sample size is small but it suggests that there is possibility of higher death in newborn with thick meconium compared to that of thin. Fifteen (thin MAS $=3$; thick MAS $=12$ ) babies went on leave against medical advice and it was difficult to predict the exact burden of mortality in MAS babies and its relation to duration of admission in our study.

The mean gestational ages of babies with thin and thick meconium were 39.5 weeks and 39.9 weeks with standard deviation of 1.7 weeks and 1.8 weeks respectively suggesting the occurrence of MAS in term and post term babies. Previous studies conducted in Nepal and other countries suggested increase in incidence of meconium stained liquor as the gestation advanced $^{9,12,13}$ but none reported MAS in preterm babies.

APGAR score less than or equal to 3 at 1 minute was seen in $27 \%$ of MAS babies with predominance in thick meconium (80.9\%-versus $19 \%)$. There was no statistical significance in the APGAR scores at 1 and 5 minutes in babies neither in those with thick nor thin meconiums. Similar results were observed in other studies. ${ }^{14,15}$

At admission, 32\% $(n=25)$ MAS babies had severe respiratory distress (Downes score less than 4) with majority being reported with thick meconium [18 $(34.6 \%)$ versus $7(28 \%)]$. Although majority of babies with thick meconium had moderate respiratory distress (Downes ' score: 4-6) at 12 hours and 24 hours from the time of admission but the difference was statistically not significant when compared in those with thin meconium. Gupta et al. ${ }^{16}$ showed that $20 \%$ of the babies had respiratory distress out of 50 babies delivered through meconium stained amniotic fluid with $21.4 \%$ having thick meconium. In a study conducted by Espinheira et al in 72 MAS babies, 11 (15.3\%) were born asymptomatic whereas $61(84.7 \%)$ had respiratory 
distress (mild, moderate and severe respiratory distress: $38.9 \%, 23.6 \%$ and $22.2 \%$ respectively). ${ }^{17}$

The incidence of birth asphyxia in MAS varies from $14.3 \%$ to $46 \%$ in various studies. ${ }^{18-20}$ In present study, $27 \%$ babies had severe birth asphyxia where majority of babies were born with thick meconium $(80.9 \%)$ but were statistically not higher than those in the born with thin meconium. A study carried out by Gupta et al. reported that $20 \%$ babies out of total 50 MAS cases developed hypoxic ischemic encephalopathy where $60 \%$ had thick meconium. ${ }^{16}$ Another study conducted by Narang et al $^{6}$ reported that significant number of MAS cases $(53.8 \%)$ developed birth asphyxia compared to those without MAS.

Many authors have demonstrated infiltration as common radiological picture in MAS whereas hyperinflation followed by infiltration were predominant in the present study and were more common with thick meconium. In a study conducted by Espinheira et al, 63.9\% MAS cases had abnormal radiological findings where diffuse patchy infiltration was predominant followed by hyperinflation, pneumothorax, consolidation and pneumomediastinum respectively. ${ }^{17}$ Yeh et $\mathrm{al}^{21}$ and Chen et $\mathrm{al}^{22}$ also demonstrated infiltration as most common radiological finding. In their studies, $x$-ray findings were not grouped into thin and thick meconium. A study conducted by Swain et $\mathrm{al}^{9}$ from Nepal also found $100 \%$ cases of MAS having abnormal $x$-ray findings with infiltration being predominant. The reason for abnormal $x$-ray in all MAS babies could be due to small sample size ( $n=15$ babies with MAS) in their study. This suggests that initial chest $x$ ray is a useful aid for the diagnosis and treatment of MAS but the outcome cannot be predicted as there are other factors which may be associated.

\section{CONCLUSIONS}

MAS is an important cause for neonatal distress in term and post term babies requiring immediate NICU admission. Babies with thick meconium require more attention and aggressive management in comparison to babies born with thin meconium. Thick meconium babies are more likely to develop respiratory distress and birth asphyxia with requirement of longer duration of oxygen therapy and respiratory support. Hyperinflation and diffuse patchy infiltrates are common radiological findings seen with higher propensity in babies with thick meconium.

\section{ACKNOWLEDGEMENTS}

Authors are indebted to the administration UCMS-TH, Bhairahawa for providing the permission and needed facilities.

Conflict of Interest: None.

\section{REFERENCES}

1. Wiswell TE, Bent RC. Meconium staining and the meconium aspiration syndrome. Unresolved issues. Pediatr Clin North Am. 1993 Oct;40(5):955-81. [PubMed]

2. Usher RH, Boyd ME, McLean FH, Kramer MS. Assessment of fetal risk in postdate pregnancies. Am J Obstet Gynecol. 1988 Feb;158(2):259-64. [PubMed]

3. Fleischer A, Anyaegbunam A, Guidetti D, Randolph G, Merkatz IR. A persistent clinical problem: profile of the term infant with significant respiratory complications. Obstet Gynecol. 1992 Feb;79(2):185-90. [PubMed]

4. Trimmer KJ, Gilstrap LC. "Meconiumcrit" and birth asphyxia. Am J Obstet Gynecol. 1991 Oct;165(4 Pt 1):1010-3. [PubMed]

5. Wiswell TE, Gannon CM, Jacob J, Goldsmith L, Szyld E, Weiss K, et al. Delivery room management of the apparently vigorous meconium-stained neonate: results of the multicenter, international collaborative trial. Pediatrics. 2000 Jan;105(1 Pt 1):1-7. [PubMed]

6. Narang A, Nair PM, Bhakoo ON, Vashisht K. Management of meconium stained amniotic fluid: a team approach. Indian Pediatr. 1993 Jan;30(1):9-13. [PubMed]
7. Rao B, Chandrashekhar GS, Rao D, Hegde P, Ghate S V. Meconium stained amniotic fluid - A prospective study. Karnataka Pediatric journal. 2011; 25(1):21-22. [Full Text]

8. SD Ashtekar, SA Renuka, KK Suresh, Kumbhar, P Gajanan, KG Nand. Clinical study of meconium aspiration syndrome in relation to birth weight and gestational maturity. International Medical Journal. 2014;1(5):189-192. [Full Text]

9. Swain P, Thapalial A. Meconium Stained Amniotic Fluid-A Potential Predictor Of Meconium Aspiration Syndrome. J Nepal Paediatr Soc. 2008;28(1):3-6. [Full Text]

10. Berkus MD, Langer O, Samueloff A, Xenakis EM, Field NT, Ridgway LE. Meconium-stained amniotic fluid: increased risk for adverse neonatal outcome. Obstet Gynecol. 1994 Jul;84(1):115-20. [PubMed]

11. Anwar Z, Butt TK, Kazi MY. Mortality in meconium aspiration syndrome in hospitalized babies. J Coll Physicians Surg--Pak JCPSP. 2011 Nov;21(11):695-9. [P

12. Bhaskar SH, Karthikeyan G, Bhat BV, Bhatia BD. Antenatal risk factors and neonatal outcome in meconium aspiration syndrome. Indian J Matern Child Health. 1997 Mar;8(1):9-12. [PubMed] 
13. Eden RD, Seifert LS, Winegar A, Spellacy WN. Perinatal characteristics of uncomplicated postdate pregnancies. Obstet Gynecol. 1987;69(3):296-299. [PubMed]

14. Gupta V, Bhatia BD, Mishra OP. Meconium stained amniotic fluid: antenatal, intrapartum and neonatal attributes. Indian Pediatr. 1996 Apr;33(4):293-7. [PubMed]

15. Wiswell TE, Henley MA. Intratracheal suctioning, systemic infection, and the meconium aspiration syndrome. Pediatrics. $1992 \mathrm{Feb} ; 89(2): 203-6$. [PubMed]

16. Kumar S, Gupta SN, Mahato IP, Giri R, Yadav A, Thakur A, et al. Maternal and fetal outcome in term labour with meconium stained amniotic fluid. Health Renaiss. 2012;10(3):198-202. [Full Text]

17. Espinheira MC, Grilo M, Rocha G, Guedes B, Guimarães H. Meconium aspiration syndrome - the experience of a tertiary center. Rev Port Pneumol. 2011 Apr;17(2):71-6. [PubMed]

18. Brown CA, Desmond MM, Lindley JE, Moore J. Meconium staining of the amniotic fluid; a marker of fetal hypoxia. Obstet Gynecol. 1957 Jan;9(1):91-103. [PubMed]
19. Miller FC, Sacks DA, Yeh SY, Paul RH, Schifrin BS, Martin $\mathrm{CB}$, et al. Significance of meconium during labor. Am J Obstet Gynecol. 1975 Jul 1;122(5):573-80. [ㅁubMed]

20. Priyadharshini M, Panicker S. Meconium stained liquor and its fetal outcome-retrospective study. IOSR-JDMS. 2013;6(2):27-31. [Full Text]

21. Yeh TF, Harris V, Srinivasan G, Lilien L, Pyati S, Pildes RS. Roentgenographic findings in infants with meconium aspiration syndrome. JAMA. 1979 Jul 6;242(1):60-3. [PubMed]

22. Chen CM, Kao HA, Shih SL. Relationship of chest roentgenographic features and outcome in meconium aspiration syndrome. Zhonghua Minguo Xiao Er Ke Yi Xue Hui Za Zhi J Zhonghua Minguo Xiao Er Ke Yi Xue Hui. 1990 Feb;31(1):24-8. [Full Text]

\section{ERRATUM}

This is updated version based on https://doi.org/10.31729/jnma.3834

Originally, in Table 2 under Birth Asphyxia in Severe category in Thick section it was 52 (66.7\%).

Now, Table 2 has been corrected to 17 (81) in this Online version, according to the letter to the Editor published on JNMA 213 Issue 2018. 